\title{
XII. On magnetostriction
}

\section{R.A. Houstoun M.A. D.Sc. Ph.D.}

To cite this article: R.A. Houstoun M.A. D.Sc. Ph.D. (1911) XII. On magnetostriction, Philosophical Magazine Series 6, 21:121, 78-83, DOI: 10.1080/14786440108637009

To link to this article: http://dx.doi.org/10.1080/14786440108637009

曲 Published online: 21 Apr 2009.

Submit your article to this journal $\pi$

Џll Article views: 4

Q View related articles $\asymp$

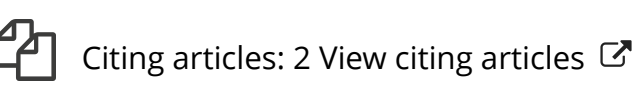


XII. On Maynetostriction. By R. A. Houstoun, M.A., D.Sc., Ph.D., Lecturer on Physical Optics in the University of Gilasgow*.

$\checkmark$ HE object of this paper is to derive a relation connecting magnetostriction with the change of magnetization produced by stress and to test it by the results of experiment. In substance the relation is not new but in method of statement it is, and the derivacion presented here is shorter and simpler than other methods. The paper also proves in a new and simple way a theorem due to Lord Kelvin.

Consider a ferro-magnetic wire hanging vertically inside a vertical solenoid with heating jacket, a pan being attached to the lower end of the wire for holding weights. Then, if hysteresis be neglected, the state of the wire may be regarded at any time as a function of the three independent variables $\mathrm{T}, \mathrm{F}$, and $\mathrm{H}$,-temperature, stretching force, and magnetic field intensity. If $\mathrm{T}, \mathrm{F}$, and $\mathrm{H}$ suffer small changes, then the heat received by the whole wire is given by

$$
d q=c d \mathrm{~T}+b d \mathrm{~F}+a d \mathrm{H} \text {. }
$$

Let $\mathrm{B}$ denote the induction in the wire, $v$ its volume, and $x$ the vertical displacement of its lower end. Then the work done on the wire when $F$ and $H$ are increased is $\mathrm{F} d x+v \mathrm{H} d \mathrm{~B} / 4 \pi$. Let $\mathrm{U}$ be the intrinsic energy of the wire and $\mathrm{S}$ its entropy. Then-

$$
\begin{aligned}
d \mathrm{U}= & d q+\mathrm{F} d x+\frac{v \mathrm{H} d \mathrm{~B}}{4 \pi} \\
=\left(c+\mathrm{F} \frac{\partial x}{\partial \mathrm{T}}+\frac{v \mathrm{H}}{4 \pi} \frac{\partial \mathrm{B}}{\partial \mathrm{l}^{\prime}}\right) d \mathrm{~T}+ & \left(b+\mathrm{F} \frac{\partial x}{\partial \mathrm{F}^{\mathrm{T}}}+\frac{v \mathrm{H}}{4 \pi} \frac{\partial \mathrm{B}}{\partial \mathrm{F}}\right) d \mathrm{~F} \\
& +\left(a+\mathrm{F} \frac{\partial x}{\partial \mathrm{H}}+\frac{v \mathrm{H}}{4 \pi} \frac{\partial \mathrm{B}}{\partial \mathrm{H}}\right) d \mathrm{H},
\end{aligned}
$$

and

$$
d \mathrm{~S}=\frac{c}{\mathrm{~T}} d \mathrm{~T}+\frac{b}{\mathrm{~T}} d \mathrm{~F}+\frac{a}{\mathrm{~T}} d \mathrm{H} .
$$

Since these are perfect differentials, we have the following six independent relations :-

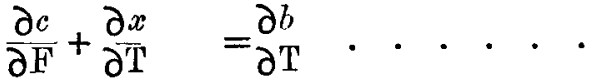

$$
\begin{aligned}
& \frac{\partial c}{\partial \mathrm{H}}+\frac{v}{4 \pi} \frac{\partial \mathrm{B}}{\partial \mathrm{T}}=\frac{\partial a}{\partial \mathrm{T}} \cdot . \quad . \quad . \quad . .
\end{aligned}
$$

* Communicated by Prof. A. Gray, F.R.S. Part of the matter of this paper has appeared in "On Two Relations in Magnetism," Proc. Roy. Soe. Edin. vol. xxx. p. 457 (1910). 


$$
\begin{aligned}
& \frac{\partial b}{\partial H}+\frac{v}{4 \pi} \frac{\partial B}{\partial H^{i}}=\frac{\partial a}{\partial H^{4}}+\frac{\partial x}{\partial H} \cdot . . . \\
& \frac{1}{\mathrm{~T}} \frac{\partial c}{\partial \mathrm{F}^{\mathrm{s}}}=\frac{\partial}{\partial \mathrm{T}}\left(\frac{b}{\mathrm{~T}}\right)=\frac{1}{\mathrm{~T}} \frac{\partial b}{\partial \mathrm{I}^{\prime}}-\frac{b}{\mathrm{~T}} \cdot . . . \\
& \frac{\mathrm{I}}{\mathrm{T}} \frac{\partial c}{\partial \mathrm{H}}=\frac{\partial c}{\partial \mathrm{T}}\left(\begin{array}{l}
a \\
\mathrm{~T}
\end{array}\right)=\frac{1}{\mathrm{~T}} \frac{\partial \alpha}{\partial \mathrm{T}}-\frac{a}{\mathrm{~T}^{2}} \cdot \ldots . \\
& \frac{\partial b}{\partial \mathrm{H}}=\frac{\partial a}{\partial \overline{\mathrm{F}}^{\prime}} \cdot \cdot \cdot \cdot \cdot \cdot \cdot
\end{aligned}
$$

and

The differential coefficients of $a, b$, and $c$ cannot be easily determined experimentally; hence we eliminate them by combining (1) with (4), (2) with (5), and (3) with (6), and obtain

and

$$
\begin{gathered}
\frac{\partial x}{\partial \mathrm{T}^{\prime}}=\frac{b}{\mathrm{~T}^{\prime}} \\
v \frac{\partial \mathrm{B}}{4 \pi}=\frac{a}{\partial \mathrm{T}}, \\
\frac{v}{4 \pi} \frac{\partial \mathrm{B}}{\mathrm{OH}^{2}}=\frac{\partial x}{\partial \mathrm{H}^{\prime}}
\end{gathered}
$$

The first of these is the well-known relation between the coefficient of linear expansion of a wire and the cooling effect produced on stretching it.

The second relation states that if the induction in a wire increases with temperature, $a$ is positive, and consequently the temperature will fall if $\mathrm{H}$ is increased; if the induction diminishes with temperature, the temperature of the wire will rise if $\mathrm{H}$ is increased. This theorem has been derived before by Lord Kelvin, ${ }^{*}$ and in quite another way. He states the result differently, - that a substance in which the magnetism diminishes with temperature when drawn gently away from a magnet experiences a cooling effect; a substance in which the magnetism increases with temperature when drawn gently away from a magnet experiences a heating effect. This cooling and heating effect is probably always masked by the irreversible heating due to Foucault currents in the wire, and to the viscous resistance to the motion of the molecular magnets.

The third relation is the one that the paper is mainly concerned with. It states, that if the induction increases when the wire is stretched, the length of the wire increases when it is magnetized, and rice versa. The connexion between

* "On the Thermo-elastic, Thermo-magnetic, and Pyro-electric Properties of Matter," Phil. Mag. [5] r. (1878) p. 4. 
magneto-striction and the effect of stress on magnetism has been worked out several times, amongst others by J. J. Thomson in his 'Applications of Mathematics to Physies and Chemistry.' The result nearest mine is given by A. Heydweiller *. His equation is

$$
\frac{\partial \mathrm{E}}{\partial \mathrm{H}}=-\frac{\mathrm{E}^{2}}{4 \pi} \frac{\partial^{2} \mathrm{~B}}{\partial p^{2}}
$$

$\mathrm{E}$ being Young's modulus for the wire and $p$ the stress per unit area of cross-section. My equation can be pat in this form. Heydweiller starts with another term in the expression for the external work done on the wire, namely, $\mathrm{HB} d v / 4 \pi$, but he makes approximations afterwards, which are equivalent to neglecting this term. Heydweiller's formula has been proved experimentally by $\mathrm{H}$. Rensingt, and has been attacked by R. Gans $\ddagger$.

On the suggestion of Dr. C.G. Knott I have tested the third relation with the data of Nagaoka and Honda\$. Before stating the results of the test I shall, however, prove the relations in another way.

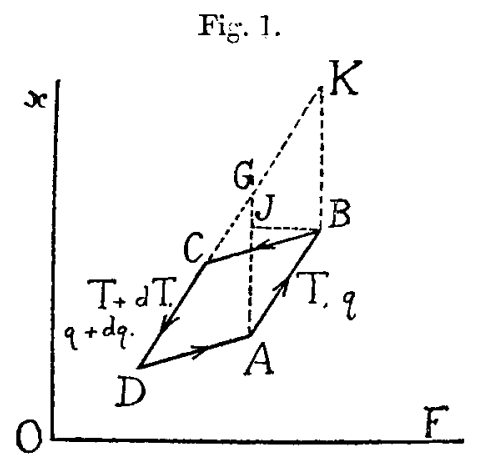

Suppose that the magnetic field intensity remains constant and that the wire is carried through the cycle depicted in the adjoining diagram, $A B$ and $C D$ being isothermals and

* "Zur Theorie der magneto-elastischen Wechselbeziehungen," Ann. d. Phys. [4] xil. (1903) p. 602 .

† "Ueber magneto-elastischeWechselbeziehungen in para-magnetischen Substanzen," Ann. d. Phys. [4] xiv. (1904) p. 36.3.

t "Magneto-striktion ferromagnetischer Körper," Ann. d. Phys. [4] xiii. (1904) p. 634. "Zur Heydweillerschen Kritik meiner Formeln betreffend Magneto-striktion ferro-magnetischer Körper," Amn. d. Phys. [4] xiv. (1904) p. 638 .

8 "On Magnetu-striction." H. Nagaoka and K. Honda. Phil. Mag. [5] xlvi. (1898) p. 260. 
Dr. R. A. Houstoun on Magnetostriction.

$\mathrm{BC}$ and $\mathrm{DA}$ adiabatics. On $\mathrm{AB}$ a quantity of heat $q$ is taken in ; on CD a quantity $q+d q$ is given out. The area of the figure is equal to the work done on the wire in the cycle and this is equal to $d q$. Hence

$$
d q=\mathrm{AC}=\mathrm{AK}=\mathrm{AG} \times \mathrm{BJ} .
$$

Also $q / \mathrm{T}=d q / d \mathrm{~T}$. Therefore, eliminating $d q$,

$$
\mathrm{AG} \times \mathrm{BJ}=q d \mathrm{~T} / \mathrm{T} \text {. }
$$

But $q$, the heat received in the isothermal $\mathrm{AB}$, is equal to $b d \mathbf{F}$, i. e. $b \overline{\mathrm{B} J}$. Substituting,

$$
\frac{b}{\mathrm{~T}}=\frac{\mathrm{AG}}{d \mathrm{~T}} .
$$

But $\mathrm{AG}$ is the alteration of $x, \mathrm{~F}$ constant in going from the one isothermal to the other; hence

$$
\frac{b}{\mathrm{I}^{\prime}}=\frac{\partial x}{\partial \mathrm{I}^{\circ}}
$$

The second relation can be proved in an analogous manner by using the $\mathrm{B}, \mathrm{H}$ diagram.

If hysteresis be not disregarded, the cycle becomes irreversible, and in place of $q / \mathrm{T}=d q / d \mathrm{~T}$ we must use

$$
\frac{q}{\mathrm{~T}}-\frac{q+d q}{\mathrm{~T}+d^{\prime} \mathrm{T}} \leqq 0 \text {. }
$$

Also the figure is no longer a parallelogram as the shape of the isothermals and adiabatics is different according to the direction in which the wire is being put through the change. In order to prove the third relation, assume that the wire is put through the cycle represented in the two following diagrams.

Fig. 2
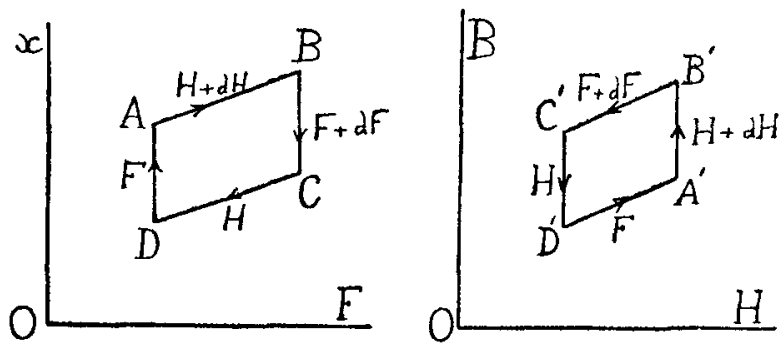

The temperature is kept constant. The two diagrams represent the same cycle, the points $\mathrm{ABCD}$ in the one figure corresponding to the points $\mathrm{A}^{\prime} \mathrm{B}^{\prime} \mathrm{C}^{\prime} \mathrm{D}^{\prime}$ in the other.

Phil. Mag. S. 6. Vol. 21. No. 121. Jan. 1911. G 
The area $A B C D$ represents the work done against the stretching force, and $v / 4 \pi$ multiplied by the area $\mathrm{A}^{\prime} \mathrm{B}^{\prime} \mathrm{C}^{\prime} \mathrm{D}^{\prime}$ the work done by the magnetic field intensity during the cycle. Therefore, by the principle of energy

$$
\mathrm{ABCD}=\frac{v}{4 \pi} \mathrm{A}^{\prime} \mathrm{B}^{\prime} \mathrm{C}^{\prime} \mathrm{D}^{\prime}
$$

Now $\mathrm{ABCD}=d \mathrm{~F} \frac{\partial x}{\partial \mathrm{H}} d \mathrm{H}$, and $\mathrm{A}^{\prime} \mathrm{B}^{\prime} \mathrm{C}^{\prime} \mathrm{D}^{\prime}=d \mathrm{H} \frac{\partial \mathrm{B}}{\partial \mathrm{F}^{\prime}} d \mathrm{~F}$. Hence substituting and dividing out by $d \mathrm{~F} d \mathrm{H}$,

$$
\frac{v}{4 \pi} \frac{\partial \mathrm{B}}{\partial \mathrm{F}}=\frac{\partial x}{\partial \mathrm{H}^{*}}
$$

Thus the third relation follows solely from the principle of energy; the second law of thermodynamics has not been used at all. This is not apparent from the former method of proof.

In the paper by Nagaoka and Honda measurements are given on the change in length of an ovoid of iron and a nickel rod of square cross-section when magnetized in the direction of the axis. The major axis of the ovoid was $20 \mathrm{cms}$. long and its minor axis $0.986 \mathrm{~cm}$.; the length of the nickel rod was $26 \mathrm{cms}$. and its breadth was $0.514 \mathrm{~cm}$. Measurements are also given on the effect of longitudinal pull on the magnetization of the same nickel rod and on the magnetization of a rod made from the same iron as the ovoid. Since we are dealing with nickel and iron we may write $B=4 \pi \mathrm{I}$. The relation to be tested then becomes

$$
\begin{aligned}
v \frac{\partial \mathrm{I}}{\partial \mathrm{F}} & =\frac{\partial x}{\partial \mathrm{H}^{\prime}}, \\
\text { or } \quad \frac{\partial \mathrm{I}}{\partial p} & =\frac{\partial a}{\partial \overline{\mathrm{H}}},
\end{aligned}
$$

if $a$ be the elongation per unit length and $p$ the stretching force per unit area of cross-section. The results are given by the following curves (fig. 3). The curves marked by circles give $\partial \mathrm{I} / \partial p$ and those marked by crosses $\partial \alpha / \partial \mathrm{H}$. They should of course coincide. The differential coefficients were formed by taking the differences of the successive figures in the tables in the article. The smaller value of $\delta p, 0 \cdot 19 \mathrm{~kg} . / \mathrm{sq} . \mathrm{mm}$. was taken.

The agreement, such as it is, is as good as that given by Kirchboff's theory which Nagaoka and Honda tested numerically. 
Similar relations can of course easily be derived for other forms of stress, torsion or hydrostatic pressure. We have only

Fig. 3.

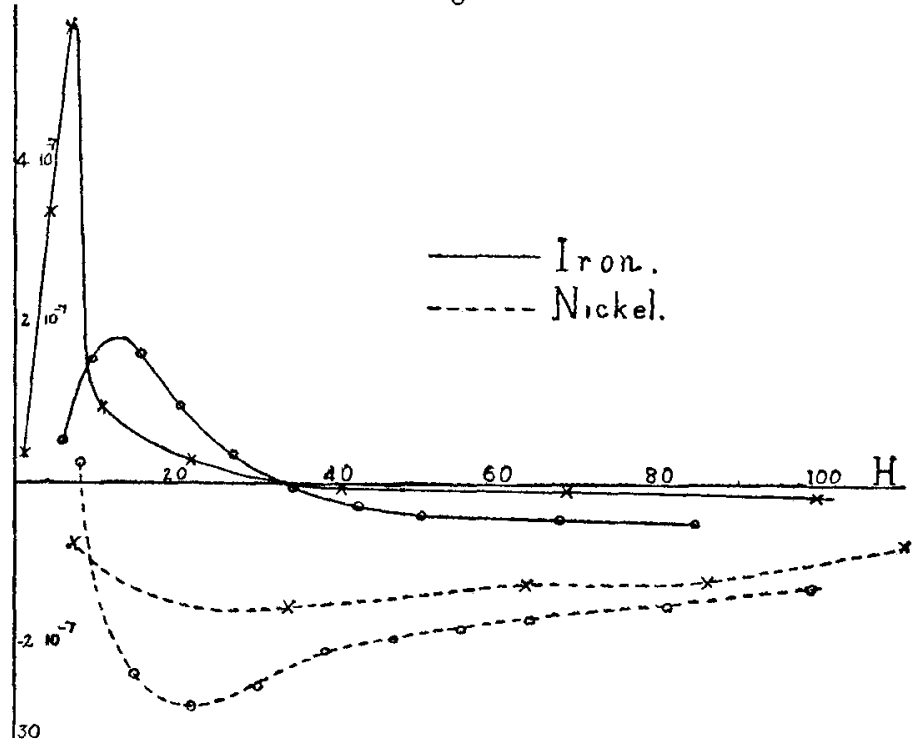

to substitute for $F$ the twisting couple or hydrostatic pressure and for $d x$ change of angle or of volume. But the change of magnetization produced by hydrostatic pressure is only of the same order as the change of volume produced. Hence in this case no agreement can be expected; the order of magnitude is, however, given correctly.

XIII. An Investigation of the Determinations of the Law of Chemical Attraction between Atoms from Physical Data. By R. D. Klegman, D.Sc., B.A., Mackinnon Student of the Royal Society*.

I $N$ this paper the writer proposes to investigate to what 1 extent the law of chemical attraction can be derived from latent heat, surface tension, and other physical properties of substances ; and an endeavour will be made to place the whole subject on a sound mathematical basis. This is highly desirable as different investigators have obtained different laws for the attraction. These laws will be briefly discussed and compared with the results obtained in this paper.

$$
\text { * Communicated by the Author. }
$$

